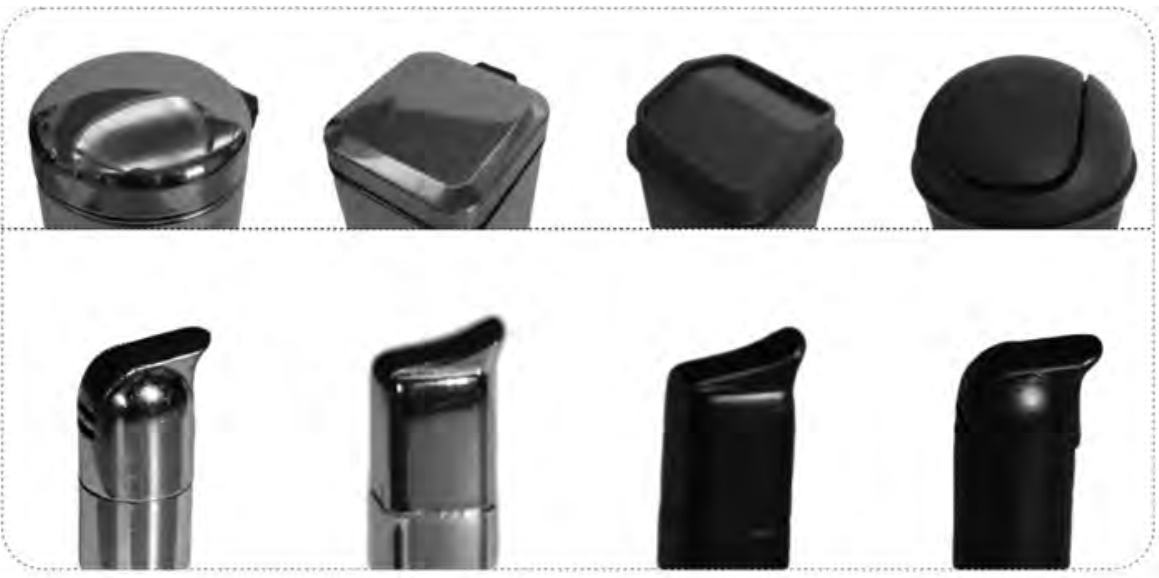

SPECIAL FILE:

FUTURES FOR MATERIALS AND INDUSTRIAL DESIGN EDUCATION

\title{
INTRODUCTION
}

It is well accepted amongst designers and academics that user-centred design is fundamental to achieving a successful product. By comprehensively understanding the people they are designing for, designers can create solutions that are more likely to connect deeply to those people's needs and desires for products. One essential aspect of industrial design for which it can prove difficult to adopt a user-centred approach is materials selection. This is because the information needs of industrial designers, with their focus on user-product interactions, have been noticeably neglected. Materials selection in industrial design, despite being an activity that in practice has always been central to designing artefacts, has received remarkably little academic scrutiny, leaving question marks over the efficacy of course content and pedagogical approach for teaching trainee designers.

Contrast this situation with materials science, which has long supported the generation of materials information to help engineers create better performing products. As a result, as a formal activity, materials selection in product design has traditionally been a technical-led and engineering dominated subject, focused on choosing materials having properties such as strength, durability and low weight that match a desired product performance at an acceptable cost.

Against this backdrop, an important new area of research that is gaining momentum involves the development of user-led approaches to materials selection. Such research is motivated by a desire to develop tools and advice that better suits industrial designers' needs and to develop an evidence base for materials and manufacturing design decisions that go beyond just the technical. Questions such as, 'what meanings do people associate with glass compared with ceramic sanitary ware?', 'which material finish should be chosen to convey the right level of glossiness?', and 'is plastic likely to be perceived as a credible material for an acoustic guitar?', can now be posed with some confidence because thinking structures, tools and selection methods are becoming available to reach 
substantiated answers. Schifferstein and Hekkert $(2008,650)$ provide a useful summary of the motivations for conducting research into the humanistic aspect of materials selection.

“...if the designer changes the product's material - let's say from aluminium to plastics - this change has consequences for its tactual and visual aesthetics, for the symbolic and social meaning attached to the product, for the emotions it can elicit, and for its durability, reliability and performance. Hence, this decision affects the way the product is experienced in multiple ways, and it will ultimately affect the quality of the life experience this product is supposed to support."

Despite its centrality in design decisions, elaboration of this experiential perspective on materials has been grossly neglected. Several factors may have contributed to the low profile that exists for 'softer' human-factors based materials and manufacturing selection activities. Such activities may be viewed as less important, less easily understood or less easily communicated than 'harder' selection activities pursued within engineering.

A primary motivation for each of the articles forming this Special File has been the articulation of the less tangible and less technical aspects of materials selection and their integration into design education. The Special File brings together the research and thoughts of five academics in the formative stages of their careers, each contributing to the growing area of user-led materials selection and product experiences, and each carrying out work that evidently has important implications for industrial design education. The authors bring international perspectives from Turkey, the Netherlands, Italy, and China. Furthermore, each author completed his / her PhD in the area of materials and design: Elvin Karana at TUDelft (2009), Valentina Rognoli at Politecnico di Milano (2004), Hengfeng Zuo at Southampton Solent University (2003), Ilse van Kesteren at TUDelft (2008) and Owain Pedgley at Loughborough University (1999). The aims of the Special File were phrased as follows.

- To identify the most important subjects influencing materials selection in contemporary industrial design, and to explore how those subjects may be best integrated into design education.

- To disseminate critical new thinking on materials and design education.

- To refresh the materials and design education agenda and stimulate debate.

- To bring together into a single source contributions from relatively young researchers who are influencing the materials education of new generations of designer.

The general emphasis within the articles is empirical research and pragmatism of application. A common thread amongst the works is exploration of materials as an element of the total 'user interface' of a product. Viewed this way, materials become an integral part of product interactions, and have a strong role to play in defining the first and lasting impressions of a product.

\section{THE ARTICLES}

The starting point for Karana's article is that designers are expected to conceive and develop products that transfer certain meanings to people who use, or come into contact with, those products. The meanings that people attribute to products are well known to be a significant factor in the experiences and relationships that ensue (Krippendorff and Butter, 2008). Karana takes a systematic approach to deconstructing the ways in which materials -as a primary attribute of productsobtain their meanings. Without a firm grip on the role of materials for creating particular meanings, Karana argues that product designers will not be able to progress beyond personal experiences and gut reaction decision-making.

At the heart of her research is the Meanings of Materials (MoM) model and tool, which provide a foundation for discourse and practical application of user- 
material-product relationships and the creation of product meanings through materials. There are some limitations of course: the MoM tool conveys information at a material family level (e.g. metal, wood) rather than specific materials within families that can have quite contrasting properties (e.g. titanium/steel, maple/ cherry). Karana ultimately concedes that those people seeking a simple causative or one-to-one relationship between materials and meanings will be disappointed: the situation is far more complex (and richer because of it). Instead, designers and students are encouraged to search for 'meaning evoking patterns', by which they can identify and manipulate various factors that influence people's attribution of meanings to materials.

Materials transmit a wonderfully diverse range of sensorial information -whether visual, tactual, acoustic, olfactory or gustatory. Such diversity, however, requires methods of classification and structuring in order to be taught to design students or harnessed in new product designs. In her article, Rognoli focuses on the idea that materials are sensorial items capable of generating sensual impact on people (Folkman, 2010). Thus, materials ought to be experienced and interacted with as a source of inspiration and understanding within design education. She argues the case that the expressive-sensorial dimension of materials is under represented and under attended-to in current professional and educational practices.

Rognoli's research includes the development of several material atlases and materials appreciation / selection tools that can be used to redress the dominance of technical-led approaches to materials selection. Initially considering tactile and photometric aspects of materials, Rognoli has specialized in ways to help designers achieve a desired chromatic (colourisation) effect in materials for new products. Intriguingly, she cites the role of neuroscience and bodily measurements as the next necessary step in developing a more robust understanding of how sensorial materials information affects people's material perception and experiences. This can be especially important in cases when, as Rognoli describes, material perception and the objective data that describes materials numerically do not match up.

The focus on tactual surface properties of materials continues in Zuo's article. Product appearances and the visual domain of user-product interaction have, until recently, dominated discussions on how people experience products. Attention to other sensory modalities - notably tactile, haptic/spatial and acoustic for consumer goods - has been relatively neglected as an area of academic study. The general ambition behind Zuo's research has been to promote greater understanding of how our sense of touch affects our experience of materials and ultimately products, whether at aesthetic, meaning or emotional levels (Desmet and Hekkert, 2007). His article provides a wide range of advice and findings that illuminate how to research the tactual dimension of materials and their relation to human perception. Zuo gathers perspectives from surveys of relevant academic fields and snapshots from his own programme of empirical and industrial research.

One of Zuo's major achievements is the creation of a Material-Aesthetics database, which is of use to designers who seek certain sensorial characteristics from a product but need guidance about which materials can deliver such characteristics. Furthermore, the database allows designers access to substantiated evidence when choosing materials on the grounds of aesthetics. This aspect of Zuo's work can be regarded as complementary to Karana's Meanings of Materials software selection tool; the main difference being Zuo's greater concentration on tests of material surfaces compared with Karana's greater concentration on people's perceptual frameworks for materials evaluation.

For students to put materials knowledge into practice, it is necessary to be skilled in the activities of materials selection. Van Kesteren's article presents the world of materials selection from the product or industrial designer's perspective, based on surveys and case studies of professional practice. Her analysis reveals a general approach to materials selection that tends from the general (e.g. plastics) through the specific (e.g. polycarbonate) to the trade-named (e.g. Lexan 104), taking a similar hierarchical approach to that described by Johnson et al. (2002). Along the way, she 
identifies various interconnected decision and information gathering cycles that lead to a Materials Selection Activities model.

In addition, van Kesteren explores the information sources that designers use to support their selection decisions, and the gaps in information provision that currently exist. The most apparent gap concerns the selection of materials based on user-product interaction and perception. This gap can be filled, she argues, through use of special selection tools that focus designers' minds on the kinds of sensorial information communicated from materials. Van Kesteren trials four materials selection tools intended to turn materials selection into a user-centred activity: a 'question tool', a 'picture tool', a 'sample tool' and a 'relation tool'. Collectively, the tools are promoted as a useful means to creating an effective material profile that spans both functional and expressive attributes of a product and therefore directly serves the ambitions of industrial designers.

In the final article, Pedgley directly tackles the subject of how to teach materials and manufacturing in an effective and engaging manner to industrial design undergraduates. The article is divided into two parts: the first concerns rationale for what to include and what to omit within a materials and design course; the second reports on a case study of improvements to the ID236 Manufacturing Materials course at Middle East Technical University, which has undergone a radical overhaul under Pedgley's guidance. He urges educators to instil in students a strongly user-centred approach to materials decision-making, for which a reassessment is needed of materials teaching languages, the role of experiential learning, development of selection skills and prioritization of constituent subject areas to be included in a course. The argumentation is driven by acknowledgment that there are 'designerly' ways of knowing and operating (Cross, 2006) and that young designers should be nurtured, at least partially, in such ways.

The case study of the ID236 course also includes an evaluation by students. Encouragingly, the findings show that students gained a generally positive experience from the course, and that the newly applied approaches to teaching and learning are appreciated and seen as effective.

\section{THE FUTURE}

It is clear from the discussions raised by all of the authors in this Special File that industrial design education has for too long borrowed an engineering perspective on materials selection, which in turn has sat uncomfortably alongside the usercentred values that define industrial design. As designers, we need to embrace the complexity of user-product interactions when making materials evaluations, and to take time to comprehend the considerable variety of factors that contribute to people's material perceptions and experiences of materials. However, we should remind ourselves that experience is a phenomenon of people rather than of products (or the materials that make up those products) and is thus not amenable to being designed in any direct sense.

As a collection of articles, the Special File is suggested to be precisely the kind of work that has been needed to strengthen the subject of materials selection for industrial design and complement existing technical-led approaches. It is great motivation to know that tomorrow's industrial designers can be provided with a more holistic foundation on which to take material decisions and that support is now available for them to concentrate on how materials choices affect people's product experiences.

Owain PEDGLEY, Guest Editor

Department of Industrial Design, METU, Ankara 


\section{REFERENCES}

CROSS, N. (2006) Designerly Ways of Knowing, Springer-Verlag, London.

DESMET, P., HEKKERT, P. (2007) Framework of Product Experience, International Journal of Design 1(1) 57-66.

FOLKMAN, M. (2010) Evaluating Aesthetics in Design: A Phenomenological Approach, Design Issues, 26 (1) 40-53.

JOHNSON K., LANGDON, P., ASHBY, M. (2002) Grouping Materials and Processes for the Designer: An Application of Cluster Analysis, Materials and Design (23: 1) 1-10.

KARANA, E. (2009) Meanings of Materials, unpublished Ph.D. Thesis, Faculty of Industrial Design Engineering, Delft University of Technology.

KESTEREN, I. van (2008) Selecting Materials in Product Design, unpublished Ph.D. Thesis, Faculty of Industrial Design Engineering, Delft University of Technology.

KRIPPENDORF, K., BUTTER, R. (2008) Semantics: Meanings and Contexts of Artefacts, H. Schifferstein, P. Hekkert, eds., Product Experience, Elsevier, San Diego; 353-76.

PEDGLEY, O. (1999) Industrial Designers' Attention to Materials and Manufacturing Processes: Analyses at Macroscopic and Microscopic Levels, unpublished Ph.D. Thesis, Department of Design and Technology, Loughborough University.

ROGNOLI, V. (2004) The Expressive-Sensorial Characterization of Materials for Design, unpublished Ph.D. Thesis, Faculty of Design, Politecnico di Milano, Milan.

SCHIFFERSTEIN, H., HEKKERT, P., eds. (2008) Product Experience, Elsevier, San Diego.

ZUO, H. (2003) Sensory Interaction with Materials in Product Design, unpublished Ph.D. Thesis, Southampton Solent University, ID No 6424783. 